\title{
Development of the first disability index for inflammatory bowel disease based on the international classification of functioning, disability and health
}

Laurent Peyrin-Biroulet, ${ }^{1}$ Alarcos Cieza, ${ }^{2,3,4}$ William J Sandborn, ${ }^{5}$ Michaela Coenen, ${ }^{2,3}$ Yehuda Chowers, ${ }^{6}$ Toshifumi Hibi, ${ }^{7}$ Nenad Kostanjsek, ${ }^{8}$ Gerold Stucki, ${ }^{3,4,9}$ Jean-Frédéric Colombel, ${ }^{10}$ the International Programme to Develop New Indexes for Crohn's Disease (IPNIC) group*

- Additional supplementary tables are published online only. To view these files please visit the journal online (http://gut. bmj.com/content/61/2.toc).

For numbered affiliations see end of article.

\section{Correspondence to}

Professor Jean-Frédéric

Colombel, Département d'Hépato-gastroentérologie, Hôpital Claude Huriez, Centre Hospitalier Universitaire Régional, 59037 Lille, France; jean-frederic.colombel@ chru-lille.fr

For author footnote see end of the article.

Accepted 26 April 2011 Published Online First 5 June 2011

\section{ABSTRACT}

Objective The impact of inflammatory bowel disease

(IBD) on disability remains poorly understood. The World Health Organization's integrative model of human functioning and disability in the International Classification of Functioning, Disability and Health (ICF) makes disability assessment possible. The ICF is a hierarchical coding system with four levels of details that includes over 1400 categories. The aim of this study was to develop the first disability index for IBD by selecting most relevant ICF categories that are affected by IBD.

Methods Relevant ICF categories were identified through four preparatory studies (systematic literature review, qualitative study, expert survey and crosssectional study), which were presented at a consensus conference. Based on the identified ICF categories, a questionnaire to be filled in by clinicians, called the 'IBD disability index', was developed.

Results The four preparatory studies identified 138 second-level categories: 75 for systematic literature review (153 studies), 38 for qualitative studies (six focus groups; 27 patients), 108 for expert survey (125 experts; 37 countries; seven occupations) and 98 for crosssectional study (192 patients; three centres). The consensus conference (20 experts; 17 countries) led to the selection of 19 ICF core set categories that were used to develop the IBD disability index: seven on body functions, two on body structures, five on activities and participation and five on environmental factors.

Conclusions The IBD disability index is now available. It will be used in studies to evaluate the long-term effect of IBD on patient functional status and will serve as a new endpoint in disease-modification trials.

Inflammatory bowel disease (IBD), encompassing Crohn's disease and ulcerative colitis, are chronic disabling disorders of the gastrointestinal tract affecting 2.2 million people in Europe and 1.4 million people in the USA. ${ }^{1}$

IBD is known to affect physical, psychological, familial and social dimensions of life. ${ }^{2}{ }^{3}$ Specific tools, such as the inflammatory bowel disease questionnaire, have been developed to assess quality of life in patients with IBD. ${ }^{4}$ However, in contrast to other chronic diseases, there has been no index available for evaluating decrements of func-

\section{Significance of this study}

What is already known about this subject?

- Inflammatory bowel disease (IBD) is a frequent disorder known to affect physical, psychological, familial, and social dimensions of life.

- Disability refers to the problems (objective) that a patient may have in different areas or health domains, whereas quality of life (subjective) refers to how he/she feels about these limitations and restrictions.

- There is no tool available for disability for IBD.

- The International Classification of Functioning, Disability and Health (ICF) provides a comprehensive and WHO standard framework to classify and describe functioning and disability in patients with any disease or health condition, including IBD.

\section{What are the new findings?}

- The comprehensive ICF core set for IBD, which is capable of capturing all specific aspects of disability that describe what it means to live with IBD, has been defined.

- The brief ICF core set for IBD, which captures the essence of the experience of patients with IBD and is used to develop the IBD disability index, has been defined.

- The first disability index for IBD (the IBD disability index) is now available.

\section{How might it impact on clinical practice in the} foreseeable future?

- The IBD disability index will be useful for clinical practice, disease modification trials and health reporting in IBD.

tion or disability for IBD to date. ${ }^{6}$ As the natural history of IBD may alter all dimensions of functioning, it would be valuable to have a practical tool covering the entire spectrum of limitations in functioning in patients with IBD. ${ }^{89}$ In this context, it is also important to take into account the impact of the patient's environment, which may improve or worsen his/her level of functioning. his paper is freely available online under the BMJ Journa gut.bmi.com/site/about/ unlocked.xhtml 
The International Classification of Functioning, Disability and Health (ICF) provides a comprehensive and World Health Organization (WHO) standard framework to classify and describe functioning, disability and health in patients with any disease or health condition, including IBD. ${ }^{10}$ The ICF is a coding system of functioning items as the basic classification units, which are called categories. ${ }^{10}$ The ICF includes more than 1400 of these categories classified according to four components. The problems associated with a disease may involve body functions, body structures and activities and participation. In addition, disability (or a decrement in functioning) is the result of an interaction between underlying health conditions and contextual factors, namely environmental and personal factors. The ICF categories are hierarchically arranged in four levels: the first or chapter level is followed with increasing specificity by the second, third and fourth levels. As the ICF is the international standard for describing functioning and disability it would be the appropriate tool to form the basis for developing an instrument to evaluate the functioning decrements in IBD.

The objective of this paper is to describe the evidence-based process leading to the development of the first disability index for IBD based on the ICF.

\section{METHODS}

The development of the IBD disability index was a cooperative effort of the International Programme to Develop New Indexes for Crohn's Disease group, the International Organization on Inflammatory Bowel Disease, the International Society of Physical and Rehabilitation Medicine, the Classification, Terminology and Standards team at WHO, and the ICF Research Branch in collaboration with the WHO Family of International Classifications Collaboration Centre in Germany (at the German Institute of Medical Documentation and Information).

This development was divided into a preparatory phase, in which information was gathered from four preparatory studies (a systematic literature review, a qualitative study, an expert survey and a cross-sectional study) and an international consensus conference. Each preparatory study and the consensus conference allowed the identification of the most relevant categories of ICF that are affected by IBD. The methodology followed by the preparatory studies and the consensus conference was published by Peyrin-Biroulet et al in $2010 .^{2}$ In a final step, the ICF categories identified during the consensus conference were operationalised using the questions of the world health survey (WHS) performed by WHO as a reference. ${ }^{11}$

\section{Preparatory studies}

\section{Systematic literature review}

The systematic literature review, whose objective was to capture the perspective of researchers, was performed in three steps: (1) searches in databases (MEDLINE, EMBASE, PSYCINFO, CENTRAL and CINAHL); (2) extraction of outcome parameters included in the studies; (3) linkage of the concepts within the outcome parameters with the ICF categories.

Eligibility criteria used in the present study were: (1) studies published in English; (2) studies published between 1999 and 2009; (3) randomised controlled trials, clinical controlled trials, cross-sectional studies, longitudinal observational studies or qualitative studies; (4) studies with a population of 10 or more patients; (5) studies with subjects 18 years of age and older; (6) studies including patients with IBD, Crohn's disease or ulcerative colitis.

\section{Qualitative study}

The qualitative study using focus group methodology was performed to identify relevant aspects of functioning as well as environmental factors from the patient perspective. Focus group sessions according to a topic guide including six open-ended questions were performed at the Mayo Clinic (Rochester, Minnesota, USA) from August to October 2009. The study protocol has been approved by the appropriate institutional review board. Each focus group included four to six adult patients with IBD consecutively seen at the Mayo Clinic. All patients had signed an informed consent form. Focus group sessions were digitally recorded and transcribed verbatim. The meaning condensation procedure was used for the data analysis. ${ }^{12}$ The resulting meaningful concepts were linked to ICF categories according to established linking rules. ${ }^{13}$ The total number of focus groups was determined by saturation, which is defined as the point during data collection at which two consecutive interviews reveal no additional information.

\section{Expert survey}

A worldwide internet-based expert survey was performed to collect relevant aspects of functioning as well as environmental factors from the perspective of the health professionals involved in the management of patients with IBD. Gastroenterologists, nurses, psychologists, digestive surgeons, dieticians, social workers and stoma therapists with at least 5 years of professional experience were asked to identify problems in functioning and contextual factors relevant to patients with IBD using openended questions. The survey was performed from February to April 2010. All answers were linked to the ICF based on established linking rules. ${ }^{14}$ Absolute and relative frequencies of the linked ICF categories were reported.

\section{Cross-sectional study}

The objective of the cross-sectional study was to describe functioning and to identify environmental factors of patients with IBD from the clinical perspective. The study took place in three centres in France (Departments of Hepato-gastroennterology of the University Hospitals of Lille, Nancy and Paris (Saint-Louis)) from May to June 2010. The protocol was approved by the appropriate French ethics committee. A 170category ICF checklist was used to collect data. In each centre, all the data were recorded by one health professional involved in the management of patients with IBD. All the patients included in the study were 18 years of age or older, presented with Crohn's disease or ulcerative colitis and had signed an informed consent form.

Detailed methods for each step have already been provided in the literature. ${ }^{14-20}$

\section{Consensus conference}

The consensus conference took place from 24 to 26 June 2010 at the Guido Zäch Institute in Nottwil, Switzerland. Participants were stratified by health profession and the country of origin and then were randomly selected to ensure a balanced representation of all important health professions and all WHOdesignated world regions. During the consensus conference, all the participants were introduced to the ICF framework, classification structure and codes, and then the ICF categories relevant for patients with IBD were identified in an iterative decisionmaking process that included discussions and voting in working groups and plenary sessions. The process was guided by a member of the ICF research branch. The ICF categories most frequently named in all four preparatory studies (so-called 
Table 1 Comprehensive ICF core set for IBD

\begin{tabular}{|c|c|c|c|c|c|}
\hline & \multicolumn{4}{|c|}{ ICF code and level } & \multirow[b]{2}{*}{ ICF category } \\
\hline & 1st & 2nd & 3rd & 4th & \\
\hline \multirow[t]{16}{*}{ Body functions (b) } & & b130 & & & Energy and drive functions \\
\hline & & b134 & & & Sleep functions \\
\hline & & b152 & & & Emotional functions \\
\hline & & & b1801 & & Body image \\
\hline & & & & b28012 & Pain in stomach or abdomen \\
\hline & & & & b28016 & Pain in joints \\
\hline & & b430 & & & Haematological system functions \\
\hline & & b435 & & & Immunological system functions \\
\hline & & b515 & & & Digestive functions \\
\hline & & b525 & & & Defecation functions \\
\hline & & b530 & & & Weight maintenance functions \\
\hline & & b535 & & & Sensations associated with the digestive system \\
\hline & & b545 & & & Water, mineral and electrolyte balance functions \\
\hline & & b640 & & & Sexual functions \\
\hline & & b660 & & & Procreation functions \\
\hline & & b810 & & & Protective functions of the skin \\
\hline \multirow[t]{2}{*}{ Body structures (s) } & & $s 540$ & & & Structure of intestine \\
\hline & & s770 & & & Additional musculoskeletal structures related to movement \\
\hline \multirow{7}{*}{$\begin{array}{l}\text { Activities and } \\
\text { participation (d) }\end{array}$} & & d230 & & & Carrying out daily routine \\
\hline & & & d5301 & & Regulating defecation \\
\hline & & $\mathrm{d} 570$ & & & Looking after one's health \\
\hline & $\mathrm{d} 7$ & & & & Interpersonal interactions and relationships \\
\hline & & $\mathrm{d} 810-\mathrm{d} 839$ & & & Education \\
\hline & & $\mathrm{d} 840-\mathrm{d} 859$ & & & Work and employment \\
\hline & & d920 & & & Recreation and leisure \\
\hline \multirow{11}{*}{$\begin{array}{l}\text { Environmental } \\
\text { factors (e) }\end{array}$} & & e110 & & & Products or substances for personal consumption \\
\hline & & & e1501 & & $\begin{array}{l}\text { Design, construction and building products and technology for gaining access to facilities } \\
\text { inside buildings for public use }\end{array}$ \\
\hline & & $\mathrm{e} 310$ & & & Immediate family \\
\hline & & e320 & & & Friends \\
\hline & & e355 & & & Health professionals \\
\hline & & e410 & & & Individual attitudes of immediate family members \\
\hline & & e420 & & & Individual attitudes of friends \\
\hline & & e425 & & & Individual attitudes of acquaintances, peers, colleagues, neighbours and community members \\
\hline & & e450 & & & Individual attitudes of health professionals \\
\hline & & e570 & & & Social security services, systems and policies \\
\hline & & e580 & & & Health services, systems and policies \\
\hline
\end{tabular}

IBD, inflammatory bowel disease; ICF, International Classification of Functioning, Disability and Health.

candidate categories) made up the starting point of the decisionmaking and consensus process. This process consisted of two major activities. In the first activity, the participants were asked to select ICF categories to be included in a so-called comprehensive ICF core set for IBD. In the second activity, the participants were requested to select the categories for the so called brief ICF core set for IBD from the list of ICF categories already included in the comprehensive ICF core set by means of a tworound ranking exercise and a final vote. The detailed method has already been provided in the literature. ${ }^{21}$

The comprehensive ICF core set is intended for use in clinical practice, in settings in which a comprehensive assessment is necessary. The brief core set captures the essence of the experience of patients with IBD. It therefore serves as the starting point for condition-specific research and basic clinical documentation.

\section{IBD disability index}

Based on the ICF categories of the brief ICF core set for IBD, a questionnaire was developed. One to two questions of the questionnaire were used to operationalise each of the ICF categories of the brief ICF core set for IBD, and whenever possible questions of the WHS were used. For other ICF categories for which no WHS questions were available, the definitions provided by the ICF were used to create the questions. The questions addressed the severity of each problem of patients with IBD in each functioning area described by the ICF categories of the brief ICF core set. Answers were given using a fivepoint Likert scale (1, no to 5 , extreme). The IBD disability index was designed to be applied by an interviewer, but a self-reported version may also be developed.

\section{RESULTS}

\section{Preparatory studies}

Systematic literature review

The literature database searches resulted in 9728 unique abstracts, of which 2579 were randomly selected for analysis. After a first analysis on abstract and a second analysis on full text, 153 studies met the inclusion criteria. The characteristics of these 153 studies are shown in supplementary table 1, available online only. Out of these 153 studies, 133 (86.9\%) included 76 different outcomes measures (eg, disease classifications/indexes, patient-reported outcome measures, clinical tests). Based on the concepts contained in these outcome measures, 155 ICF 
Table 2 Brief ICF core set for IBD

\begin{tabular}{|c|c|c|c|c|c|}
\hline & \multicolumn{4}{|c|}{ ICF code and level } & \multirow[b]{2}{*}{ ICF category } \\
\hline & 1st & 2nd & 3rd & 4th & \\
\hline \multirow[t]{5}{*}{ Body functions (b) } & & b130 & & & Energy and drive functions \\
\hline & & b134 & & & Sleep functions \\
\hline & & & b1801 & & Body image \\
\hline & & & & b28012 & Pain in stomach or abdomen \\
\hline & & b515 & & & Digestive functions \\
\hline \multirow[t]{2}{*}{ Body structures (s) } & & s540 & & & Structure of intestine \\
\hline & & s770 & & & Additional musculoskeletal structures related to movement \\
\hline \multirow[t]{4}{*}{ Activities and participation (d) } & & & d5301 & & Regulating defecation \\
\hline & & $\mathrm{d} 570$ & & & Looking after one's health \\
\hline & d7 & & & & Interpersonal interactions and relationships \\
\hline & & d810-d839 & & & Education \\
\hline \multirow{2}{*}{ Environmental factors (e) } & & e570 & & & Social security services, systems and policies \\
\hline & & e580 & & & Health services, systems and policies \\
\hline
\end{tabular}

IBD, inflammatory bowel disease; ICF, International Classification of Functioning, Disability and Health.

categories (including 75 second-level categories) were linked (see supplementary table 2, available online only).

\section{Qualitative study}

A total of 27 participants was included in six focus groups. Patients were men $(n=17)$ and women $(n=10)$, aged between 23 and 70 years (mean 44 years), with Crohn's disease $(n=16)$ or ulcerative colitis $(n=11)$. The percentage of new second-level ICF categories identified after each focus group was $94 \%$ after focus group 1, 12\% after focus group 2, 24\% after focus group 3, $7 \%$ after focus group 4 and $8 \%$ after focus group 5 . Based on the statements of the participants numerous aspects of functioning as well as environmental factors were linked to 88 ICF categories (including 38 second-level ICF categories) (see supplementary table 3 , available online only).

\section{Expert survey}

A total of 125 experts from 37 countries with various occupations (dieticians $n=24$; gastroenterologists $n=44$; nurses $n=17$; psychologists $n=9$; colorectal-surgeons $n=17$; social workers $\mathrm{n}=4$; stoma therapists $\mathrm{n}=10$ ) participated in the worldwide internet-based survey. The mean age of these experts was 46 years (SD 9.5; range 28-67). Additional demographic characteristics are summarised in supplementary table 4, available online only. Based on the statements of the participating experts 206 ICF categories (including 108 second-level categories) were identified (see supplementary table 5, available online only).

\section{Cross-sectional study}

A total of 192 patients was included in this preparatory study. Patients were men $(n=90 ; 46.9 \%)$ and women $(n=102 ; 53.1 \%)$, aged between 18 and 75 years (with a mean (SD) of 36.7 (12.9) years), with Crohn's disease ( $n=138 ; 71.9 \%)$ or ulcerative colitis $(\mathrm{n}=54 ; 28.1 \%)$. Disease duration ranged between 1 and 34 years, with a mean (SD) of 10.4 (7.7) years. A total of 126 ICF categories (including 98 second-level categories) were identified (see supplementary table 6, available online only).

Finally, the four preparatory studies identified 138 secondlevel ICF categories as candidate categories for the ICF core sets for IBD: 40 on body functions, 17 on body structures, 39 on activities and participation and 42 on environmental factors. The list of ICF categories finally presented at the conference to the participants included 448 ICF categories at all levels.

\section{ICF consensus conference}

A total of 20 experts in the field of IBD with various occupations (dieticians $\mathrm{n}=1$; gastroenterologists $\mathrm{n}=12$; nurses $\mathrm{n}=2$; psychologists $n=2$; colorectal surgeons $n=1$; social workers $n=1$; and stoma therapists $n=1$ ) from 17 countries attended the consensus conference. The iterative decision-making and consensus process involved three working groups with six to seven health professionals each. The process was facilitated by the moderator of the plenary sessions, three working group leaders and three working group assistants. The candidate ICF categories identified in the four preparatory studies made up the starting point of this process. The group decisions were presented and discussed at several plenary sessions. The participants of the conference decided on the ICF categories to be included in the comprehensive and the brief ICF core set for IBD.

The comprehensive ICF core set for IBD includes 36 ICF categories of all components of the classification. It is made up of 16 body functions (44.4\%), two body structures (5.6\%), seven activities and participation categories (19.4\%) and 11 environmental factors (30.6\%). Table 1 shows the ICF categories included in the comprehensive ICF core sets for IBD.

Based on the comprehensive ICF core set for IBD the participants of the conference decided in three ranking rounds on the selection of the categories for the brief ICF core set. According to a final cut-off decision they selected 19 categories for the brief ICF core set for IBD, which represents nearly $53 \%$ of the categories of the comprehensive ICF core set. Seven categories were chosen from the component body functions, two from body structures, five from activities and participation and five from environmental factors, respectively (table 2 ).

\section{IBD disability index}

In line with the results of the consensus conference the IBD disability index was established. In total, it contains 28 
Figure 1 Inflammatory bowel disease disability index.

PLEASE READ ALOUD THIS INSTRUCTIONS TO THE PATIENT

The first question is about the overall health of the patient, including both physical and mental health.

\begin{tabular}{|l|l|l|l|l|l|}
\hline ANSWERS: 1 = Very good; $\mathbf{2}=$ Good; 3 = Moderate; $4=$ Bad; 5 = Very bad & 1 & 2 & 3 & 4 & 5 \\
\hline Overall Health & & & & \\
\hline 1. In general, how would you rate your health today? & & & & \\
\hline
\end{tabular}

PLEASE READ ALOUD THESE INSTRUCTIONS TO THE PATIENT

Now I would like to review different functions of your body and activities of daily life. When answering these questions, I would like you to think about the last week, taking both good and bad days into account. When I ask about difficulty / problem, I would like you to consider how much difficulty / problem you have had, on an average, in the past week, while doing the activity in the way that you usually do it. By difficulty I mean that you require increased effort, that you have discomfort or pain, or that the activity is slower or that there are other changes in the way you do the activity. Please answer this question taking into account any assistance you have available.

(Read and show scale to respondent).

\begin{tabular}{|c|c|c|c|c|c|}
\hline ANSWERS: $\mathbf{1}=$ None; $\mathbf{2}=$ Mild; $\mathbf{3}=$ Moderate; $\mathbf{4}=$ Severe; $\mathbf{5}=\mathrm{E}$, & 1 & 2 & 3 & 4 & 5 \\
\hline \multicolumn{6}{|l|}{ Sleep and Energy } \\
\hline \multicolumn{6}{|l|}{$\begin{array}{l}\text { 2. Overall in the last week, how much of a problem did you have with sleeping, such as falling asleep, waking up frequently } \\
\text { during the night or waking up too early in the morning? (b134) }\end{array}$} \\
\hline \multicolumn{6}{|l|}{$\begin{array}{l}\text { 3. In the last week, how much of a problem did you have due to not feeling rested and refreshed during the day (e.g. feeling } \\
\text { tired, not having energy)? (b130) }\end{array}$} \\
\hline \multicolumn{6}{|l|}{ Affect } \\
\hline \multicolumn{6}{|l|}{ 4. Overall in the last week, how much of a problem did you have with feeling sad, low or depressed? (b152) } \\
\hline \multicolumn{6}{|l|}{ 5. Overall in the last week, how much of a problem did you have with worry or anxiety? (b152) } \\
\hline \multicolumn{6}{|l|}{ Body Image } \\
\hline \multirow{2}{*}{\multicolumn{6}{|c|}{$\begin{array}{l}\text { 6. Overall in the last week, how much of a problem did you have with the way your body or body parts looked? (b1801) } \\
\text { Pain }\end{array}$}} \\
\hline & & & & & \\
\hline 7. Overall in the last week, how much of stomach or abdomen aches or pains did you have? (b28012) & & & & & \\
\hline
\end{tabular}

\begin{tabular}{|l|l|l|l|l|l|}
\hline ANSWERS: 1 = None; $\mathbf{2}$ = Mild; 3 = Moderate; 4 = Severe; 5 = Extreme or cannot do & 1 & 2 & 3 & 4 & 5 \\
\hline
\end{tabular}

\begin{tabular}{|c|c|c|c|c|}
\hline Regulating defecation & & & & \\
\hline $\begin{array}{l}\text { 8. Overall in the last week, how much difficulty did you have coordinating and managing defecation including } \\
\text { getting to an appropriate place for defecation and cleaning oneself after defecation? (d5301) }\end{array}$ & & & & \\
\hline Looking after one's health & & & & \\
\hline $\begin{array}{l}\text { 9. Overall in the last week, how much difficulty did you have looking after your health, including maintaining a } \\
\text { (d570) }\end{array}$ & & & & \\
\hline Interpersonal Activities & & & & \\
\hline 10. Overall in the last week, how much difficulty did you have with personal relationships? (d7) & & & & \\
\hline 11. Overall in the last week, how much difficulty did you have with participation in the community? (d920) & & & & \\
\hline Work and Education & & & & \\
\hline 12. Overall in the last week, how much difficulty did you have with work or household activities? (d840-d859) & & & & \\
\hline 13. Overall in the last week, how much difficulty did you have with school or studying activities? (d\& & & & & \\
\hline
\end{tabular}

13. Overall in the last week, how much difficulty did you have with school or studying activities? (d810-d899)

(b525) Number of liquid or very soft stools in the last week

(b515) Body mass index (BMI):

(b515) Do you feel that you have lost weight in the last week?

Blood in stool (weekly average):

$\mathrm{kg} / \overline{\mathrm{m}^{2}}$

(s770)

Is arthritis or arthralyja prage:
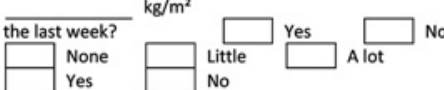

Please rate the extent to which the following aspects of the patient's
and activities of daily life, which you have reviewed with the patient.

ANSWERS: NA = Not applicable; 1 = No positive effect; $\mathbf{2}=$ Mild positive effect; 3 = Moderate positive effect: $4=$ Severe positive effect: $5=$ Extreme positive effect

+14 . Overall in the last week, did the medication the patient take alleviate her/his problems and difficulties? (e1100)

+15 . Overall in the last week, did the food the patient take alleviate her/his problems and difficulties? (e1101)

+16 . Overall in the last week, did the patient's family alleviate her/his problems and difficulties? (e310)

+17 . Overall in the last week, did health professionals alleviate the patient's problems and difficulties? (e355)

ANSWERS: NA $=$ Not applicable; 1 = No negative effect; $\mathbf{2}=$ Mild negative effect; 3 = Moderate negative effect;

$4=$ Severe negative effect; $5=$ Extreme negative effect

-14 . Overall in the last week, did the medication the patient take worsen her/his problems and difficulties? (e1100)

-15 . Overall in the last week, did the food the patient take worsen her/his problems and difficulties? (e1101)

-16. Overall in the last week, did the patient's family worsen her/his problems and difficulties? (e310)

-17 . Overall in the last week, did health professionals worsen the patient's problems and difficulties? (e355)

\begin{tabular}{|l|l|}
\hline ANSWERS: $1=$ No; $\mathbf{2}=$ yes & $\mathbf{2}$ \\
\hline Social security and health services, systems and policies & \\
\hline 18. Does the patient benefit from the support he or she needs from the social security system? (e570) & \\
\hline 19. Does the patient receive the health care he or she needs? (e580) & \\
\hline
\end{tabular}

19. Does the patient receive the health care he or she needs? ( 5580$)$

questions (figure 1). The first question asks about the general health of the patient. The next 17 questions address the ICF categories of the brief ICF core set for IBD that correspond to the components body functions, body structures and activities and participation. The last 10 questions address the environmental factors. As environmental factors can have either a positive or a negative effect on the extent of disability, the questions are paired. One question of each pair addresses the extent to which the environmental factor, such as medication, represents a facilitator during the previous week, the other asks whether the environmental factor was a barrier. For all 28 questions, the code of the ICF category that they address is written.

\section{DISCUSSION}

In this paper, we describe the evidence-based process followed to develop the first disability index for IBD. IBD is a chronic disabling condition. ${ }^{2} 8$ Therefore, there was a need to develop a specific instrument capable of evaluating disability in IBD. The formal consensus process integrating evidence from four preparatory studies and expert knowledge at the ICF core set conference for IBD led to the definition of a comprehensive and a brief ICF core set for IBD. The comprehensive ICF core set for IBD is capable of capturing all specific aspects of disability that describe what it means to live with IBD. The brief ICF core set for IBD was used to develop the IBD disability index that can be used in studies to evaluate the long-term effect of IBD on patient functional status and as a new endpoint in clinical trials aimed at changing the clinical course of the disease. The final aim is to obtain a single number that represent the level of disability and that will allow data comparison across healthcare settings, countries, and at different time points. In the following paragraphs we concentrate on the relevance of the 19 ICF 
categories included in the brief ICF core set for IBD that went into the disability index.

Body functions, energy and drive functions (ICF code b130) are frequently impaired in patients with IBD. The prevalence of fatigue ranges from $41 \%$ to $48 \%$ in patients with IBD in remission. Data are conflicting on whether fatigue severity is proportional to disease severity or activity. ${ }^{22}$ Ranjbaran et al ${ }^{23}$ showed that patients with IBD have significant sleep disturbance (b134 Sleep functions) even when their disease is not active. As is the case with most chronic illnesses, there is a higher rate of anxiety and depressive symptoms (b152 Emotional functions) in IBD than in the population at large. ${ }^{24}$

Body image (b1801) is another ICF category in the comprehensive and brief ICF core sets for IBD. It is well known that body image is negatively affected by surgery. ${ }^{25}$ Importantly, not only ileostomy but also an ileoanal pouch anal anastomosis can have a negative impact on body image and cosmesis when performed using an open surgical procedure. ${ }^{26}$

Abdominal pain (b28012 Pain in stomach and abdomen) is frequent in patients with IBD. Digestive functions (b515 Absorption of nutrients, tolerance to food, etc.) and defecation functions (b525 Faecal continence, faecal consistency, frequency of defecation, etc.) are also frequently impaired over the course of IBD. Anorectal function appears to be altered in many patients with Crohn's disease even in the absence of macroscopic anorectal disease. ${ }^{27}$ This may be due to histological alterations in the enteric nervous system. ${ }^{8}$

Following the selection process of body structures, structure of the intestine (s540) and musculoskeletal structures (s770: Additional musculoskeletal structures related to movement) were included in the brief ICF core set for IBD. IBD are chronic, progressive, destructive diseases. Crohn's disease may lead to bowel damage (stricture, fistula, abscess) while ulcerative colitis can be associated with mucosal lesions. ${ }^{28} 29$ Ankylosing spondylitis and rheumatoid arthritis, frequently associated with IBD, can also lead to joint damage. ${ }^{8}$

Regarding activities and participation, work and employment (d840-d859) is the only category that has been widely assessed in IBD2. Even though patients with IBD may attain a similar level of education ( $d 810-\mathrm{d} 839$ ) to that of the general population, students and young adults have to face missed school time. ${ }^{30} 31$ The participants of the conference also included regulating defecation (d5301), looking after one's health (d570), and interpersonal interactions and relationships (d7) in the brief ICF core set for IBD because they felt that these categories are fundamental to describe the experience of living with IBD.

Five environmental factors were included in the brief ICF core set for IBD. The participants agreed that health and social systems, services and policies available for people with IBD in each country are important factors acting as major facilitators or barriers. The other environmental factors included in the brief ICF core set addressed food and drugs as well as the support provided by the family.

There are some limitations of the project up to the consensus conference that should be mentioned. First, in the qualitative study we performed six focus groups following the strategy of saturation during data analyses. However, participants in a seventh focus group could still have reported new themes and concepts not yet reported. Second, the samples of the qualitative and empirical studies consisted of persons coming from the USA and France, respectively. This might have influenced the results of both studies. To address this limitation and to have a crosscultural perspective of functioning and disability, in addition to the ICF categories identified in the qualitative and empirical studies, the results of the international expert survey and the systematic review were also presented to the participants of the international consensus conference.

The objective of the next phase will be to test and validate the IBD disability index, and in particular to (1) assess the psychometric properties (reliability, validity, and sensitivity to change) of the index, (2) compare its sensitivity to change after treatment with biological agents using a subgroup of patients and (3) study whether the data collected based on the index reflects the hypothesised single latent dimension-functioning-and whether the selected response options express a clearly defined ordered sequence.

In conclusion, a formal consensus process integrating evidence from preparatory studies and expert opinion based on the ICF framework and classification led to the definition of the brief ICF core set for IBD, which was then used to develop the first disability index for IBD. Since functioning and disability are increasingly being taken into account in assessing the impact of chronic diseases on the individual, as well as the effectiveness of treatments on the natural course of the disease, having a disability index for IBD will be useful for clinical practice, disease modification trials and health reporting in IBD. The fact that this tool is grounded in the international standard language of the ICF will ensure that the IBD disability index will be both universally applicable and well accepted.

\section{Author affiliations}

${ }^{1}$ Department of Hepato-gastroenterology, Inserm U954, University Hospital of Nancy-Brabois, Vandoeuvre-lès-Nancy, France

${ }^{2}$ Institute for Health and Rehabilitation Sciences (IHRS), Research Unit for Biopsychosocial Health, Ludwig-Maximilians-University, Munich, Germany

${ }^{3}$ International Classification of Functioning, Disability and Health (ICF) Research Branch in collaboration with the World Health Organisation Collaborating Centre for Family of International Classifications (WHO-FIC CC) in Germany at German Institute of Medical Documentation and Information (DIMDI), Munich, Germany

${ }^{4}$ Swiss Paraplegic Research, Nottwil, Switzerland

${ }^{5}$ Division of Gastroenterology, University of California San Diego, La Jolla, California, USA

${ }^{6}$ Department of Gastroenterology, Rambam Health Care Campus, Bat Galim, Haifa, Israel

${ }^{7}$ Department of Internal Medicine, Division of Gastroenterology and Hepatology, Keio University School of Medicine, Tokyo, Japan

${ }^{8}$ Classification, Terminology and Standards (CTS), World Health Organisation (WHO), Geneva, Switzerland

${ }^{9}$ Department of Health Sciences and Health Policy, University of Lucerne, Lucerne and Nottwil, Switzerland

${ }^{10}$ Department of Hepato-gastroenterology, Huriez Hospital, University Hospital of Lille, Lille, France

\section{Author footnote}

*The IPNIC group: Walter Reinisch and Herbert Tilg (Austria); Michael Kamm (Australia); Geert D'Haens, Edouard Louis and Geert Van Assche (Belgium); Brian Feagan and E. Jan Irvine (Canada); Pierre Michetti (Switzerland); Toshifumi Hibi (Japan); Jürgen Schölmerich and Stefan Schreiber (Germany); Pia Munkholm (Denmark); Julian Panes (Spain); Jean-FrédéricColombel, Jacques Cosnes, Marc Lémann, Maïté Lewin, Jean-Yves Mary, Benjamin Pariente and Laurent Peyrin-Biroulet (France); Simon Travis (UK); Yehuda Chowers (Israel); Silvio Danese and Maurizio Vecchi (Italy); Daan W. Hommes (The Netherlands); Tom Oresland (Norway); Joel Fletcher, Edward V Loftus Jr., William J. Sandborn and Bruce E. Sands (USA).

Acknowledgements The authors would like to thank all the people who were actively involved in the qualitative study (WA Faubion, WJ Tremaine, SV Kane, Loftus EV Jr., DS Pardi and KA Hanson at the Mayo Clinic, Rochester, USA) and the cross-sectional study (G Meulin, University Hospital, Lille, France; F Salaun, University Hospital, Nancy, France; B Pariente, Saint-Louis Hospital, Paris, France). Their special thanks also go to all the experts who participated in the internet-based expert survey. The authors are most grateful for the contributions made by the following members of the ICF Research Branch of the WHO-FIC CC for their invaluable support during data analysis and the conference: U Achleitner, S Berno, C Bostan, M Carlström, A Haas, H Gall, M Kirschneck, B Kollerits, M Lückenkemper, P Quinones, N Sahakyan, KU Saum, M Selb, K Stegmüller. Finally, special thanks go to all the following experts attending the consensus conference: $F$ Albersnagel 
(University Medical Center, Groningen, The Netherlands), Y Bailey (The Adelaide and Meath Hospital incorporating the National Children's Hospital, Ireland), Y Chowers (Rambam Health Care Campus Bat Galim, Haifa, Israel), J Colwell (University of Chicago Medical Center, USA), C Coulthard (Joseph and Wolf Lebovic Health Complex, Canada); G Fiorino (Istituto Clinico Humanitas, Rozzano, Milan, Italy), D Franchimont (Erasme University Hospital, Free University of Brussels, Belgium), A Girdwood (Vincent Pallotti Hospital Pinelands, Groote Schuur Hospital, University of Cape Town, South África), T Hibi (Keio University School of Medicine, Japan), K Holbrook (Gloucestershire Hospitals NHS Foundation Trust, Cheltenham General Hospital, England), M Lomer (Guy's and St Thomas' NHS Foundation Trust and King's College London, England), A Mikocka-Walus (School of Nursing and Midwifery, University of South Australia, Australia), I Nion-Larmurier (Saint Antoine Hospital, Paris, France), I Ordàs (Hospital Clínic, Barcelona, Spain), G Rogler (University Hospital of Zürich, Zürich Centre for Integrative Human Physiology, University of Zürich, Switzerland), A Maria Sambuelli (Bonorino Udaondo Gastroenterology Hospital, Argentina), WJ Sandborn (Mayo Clinic, Rochester, USA), J Sellin (Baylor College of Medicine, USA), J de Silva (University of Kelaniya, Colombo North Teaching Hospital, Sri Lanka), A Spinelli (Instituto Clinico Humanitas - IRCCS, Italy), H Tavakkoli (Isfahan University of Medical Sciences, Poursina Hakim Research Institute, Iran).

Funding The preliminary studies and the consensus conference were funded by the French association INTEST-INFO (www.intestinfo.com). Abbott provided funding for the IPNIC programme. F Péretz (independent medical writer) provided medical writing and editing services in the development of the manuscript. Financial support for these services was provided by Abbott.

Competing interests J-F Colombel, J Cosnes, T Oresland, L Peryin-Biroulet, W Reinisch, W Sandborn, J Schölmerich, S Travis, G Van Assche, and M Vecchi have received research support from and/or served as consultants for Abbott Laboratories. No potential conflicts (financial, professional, or personal) relevant to the manuscript for the other authors.

\section{Patient consent Obtained.}

Ethics approval Qualitative study: the study protocol has been approved by the appropriate institutional review board (Mayo Clinic). Cross-sectional study: the protocol was approved by the appropriate French ethics committee.

Contrbutors All the authors were involved with the whole process (from study design to critical revision of the manuscript) and maintained complete control over the direction and content of the paper. Abbott did not review nor approve the manuscript content, nor have any influence over the manuscript content.

Provenance and peer review Not commissioned; externally peer reviewed.

\section{REFERENCES}

1. Loftus EV Jr. Clinical epidemiology of inflammatory bowel disease: incidence, prevalence, and environmental influences. Gastroenterology 2004-126:1504-17.

2. Peyrin-Biroulet L, Cieza A, Sandborn WJ, et al. Disability in inflammatory bowel diseases: developing ICF Core Sets for patients with inflammatory bowel diseases based on the International Classification of Functioning, Disability and Health. Inflamm Bowel Dis 2010;16:15-22.

3. Casellas F, López-Vivancos J, Vergara M, et al. Impact of inflammatory bowel disease on health-related quality of life. Dig Dis 1999:17:208-18.

4. Love JR, Irvine EJ, Fedorak RN. Quality of life in inflammatory bowel disease. J Clin Gastroenterol 1992:14:15-19.

5. Guyatt G, Mitchell A, Irvine EJ, et al. A new measure of health status for clinical trials in inflammatory bowel disease. Gastroenterology 1989;96:804-10.

6. Ebers GC, Heigenhauser L, Daumer M, et al. Disability as an outcome in MS clinical trials. Neurology 2008;71:624-31

7. Goekoop-Ruiterman YP, de Vries-Bouwstra JK, Allaart CF, et al. Clinical and radiographic outcomes of four different treatment strategies in patients with early rheumatoid arthritis (the BeSt study): a randomized, controlled trial. Arthritis Rheum 2008;58(2 Suppl):S126-35
8. Peyrin-Biroulet L, Loftus EV Jr, Colombel JF, et al. Long-term complications, extraintestinal manifestations, and mortality in adult Crohn's disease in populationbased cohorts. Inflamm Bowel Dis 2011;17:471-8.

9. Peyrin-Biroulet L, Loftus EV Jr, Colombel JF, et al. The naturalhistory of adult Crohn's disease in population-based cohorts. Am J Gastroenterol 2010;105:289-97.

10. World Health Organization. International Classification of Functioning, Disability and Health (ICF). Geneva: WHO, 2001. http://www.who.int/classifications/icf/en (accessed 27 Dec 2010).

11. World Health Organization. World Health Report 2000-Health Systems: Improving Performance. Geneva, Switzerland: WHO, 2000. http://www.who.int/whr/ 2000/en/whr00 en.pdf (accessed 17 Feb 2010).

12. Karlsson G. Psychological Qualitative Research from a Phenomenological Perspective. Stockholm: Almquist andWiskell International, 1995

13. Cieza A, Geyh S, Chatterji S, et al. ICF linking rules: an update based on lessons learned. J Rehabil Med 2005;37:212-18.

14. Gradinger $\mathbf{F}$, Köhler $B$, Khatami $R$, et al. Problems in functioning from the patient perspective using the International Classification of Functioning, Disability and Health (ICF) as a reference. J Sleep Res. Published Online First: 19 July 2010. doi:10.1111/ j.1365-2869.2010.00862.x.

15. Avila CC, Cabello M, Cieza A, et al. Functioning and disability in bipolar disorders: a systematic review of literature using the ICF as a reference. Bipolar Disord 2010;12:473-82.

16. Post MW, Kirchberger I, Scheuringer M, et al. Outcome parameters in spinal cord injury research: a systematic review using the International Classification of Functioning, Disability and Health (ICF) as a reference. Spinal Cord 2010:48:522-8.

17. Kirchberger I, Sinnott A, Charlifue S, et al. Functioning and disability in spinal cord injury from the consumer perspective: an international qualitative study using focus groups and the ICF. Spinal Cord 2010;48:603-13.

18. Tschiesner U, Becker S, Cieza A. Health professional perspective on disability in head and neck cancer. Arch Otolaryngol Head Neck Surg 2010;136:576-83.

19. Scheuringer $\mathbf{M}$, Kirchberger I, Boldt C, et al. Identification of problems in individuals with spinal cord injury from the health professional perspective using the ICF: a worldwide expert survey. Spinal Cord 2010:48:529-36.

20. Holper L, Coenen M, Weise A, et al. Characterization of functioning in multiple sclerosis using the ICF. J Neurol 2010;257:103-13.

21. Cieza A, Kirchberger I, Biering-Sørensen F, et al. ICF core sets for individuals with spinal cord injury in the long-term context. Spinal Cord 2010;48:305-12.

22. vanLangenberg DR, Gibson PR. Systematic review: fatigue in inflammatory bowe disease. Aliment Pharmacol Ther 2010;32:131-43.

23. Ranjbaran Z, Keefer L, Farhadi A, et al. Impact of sleep disturbances in inflammatory bowel disease. J Gastroenterol Hepatol 2007:22:1748-53.

24. Graff LA, Walker JR, Bernstein CN. Depression and anxiety in inflammatory bowe disease: a review of comorbidity and management. Inflamm Bowel Dis 2009:15:1105-18.

25. Muller KR, Prosser R, Bampton $\mathrm{P}$, et al. Female gender and surgery impair relationships, body image, and sexuality in inflammatory bowel disease: patient perceptions. Inflamm Bowel Dis 2010;16:657-63.

26. Polle SW, Dunker MS, Slors JF, et al. Body image, cosmesis, quality of life, and functional outcome of hand-assisted laparoscopic versus open restorative proctocolectomy: long-term results of a randomized trial. Surg Endosc 2007;21:1301-7.

27. Mueller MH, Kreis ME, Gross ML, et al. Anorectal functional disorders in the absence of anorectal inflammation in patients with Crohn's disease. Br J Surg 2002;89:1027-31.

28. Pineton de Chambrun G, Peyrin-Biroulet $L$, Lémann $M$, et al. Clinical implications of mucosal healing for the management of IBD. Nat Rev Gastroenterol Hepatol 2010; 7:15-29.

29. Pariente B, Cosnes J, Danese $S$, et al. Development of the Crohn's disease digestive damage score, the Lemann score. Inflamm Bowel Dis. Published Online First: 28 November 2010. doi:10.1002/ibd.21506.

30. Marri SR, Buchman AL. The education and employment status of patients with inflammatory bowel diseases. Inflamm Bowel Dis 2005:11:171-7.

31. Calsbeek H, Rijken M, Bekkers MJ, et al. School and leisure activities in adolescents and young adults with chronic digestive disorders: impact of burden of disease. Int J Behav Med 2006:13:121-30. 